\title{
3D printed Polylactid Acid based porous scaffold for bone tissue engineering: an in vitro study
}

\author{
SIMONA BODNÁROVÁ ${ }^{1 *}$, SYLVIA GROMOŠOVÁ ${ }^{2}$, RADOVAN HUDÁK ${ }^{1}$, \\ JÁN ROSOCHA ${ }^{2}$, JOZEF ŽIVČÁK ${ }^{1}$, JANA PLŠÍKOVÁ ${ }^{2}$, MAREK VOJTKO ${ }^{3}$, TEODOR TÓTH ${ }^{2}$, \\ DENISA HARVANOVÁ ${ }^{1}$, GABRIELA IŽARIKOVÁ ${ }^{4}$, L'UBOŠ DANIŠOVIČ ${ }^{5,6}$ \\ ${ }^{1}$ Department of Biomedical Engineering and Measurement, Faculty of Mechanical Engineering, \\ Technical University of Kosice, Slovakia. \\ ${ }^{2}$ Associated Tissue Bank, Faculty of Medicine P. J. Safarik University and L. Pasteur University Hospital Kosice, Slovakia. \\ ${ }^{3}$ Institute of Materials Research, Slovak Academy of Sciences, Kosice, Slovakia. \\ ${ }^{4}$ Department of Applied Mathematics and Informatics, Faculty of Mechanical Engineering, Technical University of Kosice, Slovakia \\ ${ }^{5}$ Institute of Medical Biology, Genetics and Clinical Genetics, Faculty of Medicine, Comenius University in Bratislava, Slovakia. \\ ${ }^{6}$ Regenmed Ltd., Research Division, Bratislava, Slovakia.
}

\begin{abstract}
Purpose: The objective of this study was to fabricate PLA-based porous scaffold by 3D printing technology and to evaluate their cytotoxicity and biocompatibility under in vitro conditions in respect to bone tissue engineering. Material and methods: Pure PLA in filamentous form was processed via 3D printing technology of fused filament fabrication into porous scaffolds. The structure and porosity of scaffolds were measured by metrotomography. PLA scaffolds were pre-treated by human serum, foetal bovine serum and complete cell culture medium to enhance bio-attractivity of the scaffold's surface for the adherence of the cells. Cells were enzymatically isolated from the periosteum of the proximal tibia and then expanded in monolayer. Periosteum-derived osteoprogenitors (PDOs) were seeded on the pre-treated PLA scaffolds and subsequent cell proliferation was measured by commercially available cell proliferation assay. Adherence of PDOs on the PLA scaffold was confirmed by scanning electron microscopy (SEM). Results: Prepared scaffolds had well-defined structure and were characterized by uniform distribution of pores. They were non-toxic and biocompatible with PDOs, however, PLA scaffold with the periosteum-derived progenitor cells was significantly better in the group of scaffolds pre-treated with normal human serum. Conclusions: The obtained PLA porous scaffolds favored attachment of periosteum derived progenitors and proliferation, furthermore, cells penetrated into the scaffold through the interstitial pores which was meaningful for cytocompatibility evaluation.
\end{abstract}

Key words: polylactic acid (PLA), 3D printing, porous scaffold, periosteum-derived osteoprogenitors (PDOs), tissue engineering

\section{Introduction}

Regeneration of massive bone defects as a consequence of trauma, infection, tumor resection and inborn defects still represent major treatment challenge in orthopedics and trauma surgery. Variety of treatment approaches have been developed and introduced such as autologous bone grafts, allografts and xenografts in clinic [4]. Generally accepted utilization of autologous bones suffers from many problems, including limited availability of bone volume, donor site morbidity, and enormous economic burden [7]. Due to these drawbacks, scientists and physicians have been forced to find new therapeutic techniques.

Additive manufacturing techniques also known as Rapid Prototyping (RP) represent powerful tools to fabricate scaffolds for tissue engineering applications and regenerative medicine. These model-based technologies build porous 3-dimensional (3D) custom-made scaffolds in a controlled manner layer-by-layer, through material deposition on a stage [20]. Fused filament

\footnotetext{
* Corresponding author: Simona Bodnárová, Department of Biomedical Engineering and Measurement, Faculty of Mechanical Engineering, Technical University of Kosice, Letna 9, 04200 Kosice, Slovakia. E-mail: simona.bodnarova@tuke.sk

Received: July 19th, 2019

Accepted for publication: October 10th, 2019
} 
fabrication (FFF) is a technique based on process of melting of polymers. Filaments of polymers are fed into a heated nozzle which melts the polymer and affords 3D positioning of the polymer melts to form strands [3]. This approach combines controlled pumping technology and a $\mathrm{CAD} / \mathrm{CAM}$ system to produce precise and reproducible fabrication of $3 \mathrm{D}$ structures with well-defined programmed geometries [2], [20].

The character and properties of scaffold depends not only on printing technology but also on the material used to produce 3D structure. Generation of useful polymeric scaffolds for tissue engineering must account for several parameters including scaffold degradation rates, biocompatibility, host tissue integration, mechanical stability, and even optimal pore size [11]. Until now, various polymers have been successfully applied to fabricate scaffolds, including aliphatic polyesters such as poly(lactic acid) (PLA), poly(glycolic acid) (PGA) and their copolymers [19]. For instance, PLA attracted considerable attention in biomedicine and environmental applications because of its excellent biodegradability, mechanical properties, and biocompatibility. Moreover, the Food and Drug Administration (FDA) has approved PLA for a variety of biomedical applications [17].

PLA-based scaffolds have been previously investigated as a synthetic polymeric biomaterial for cartilage implant development, whose properties, such as mechanical strength, degradation rate and dimensions can all be easily controlled [9]. Another studies have been carried out to evaluate their potential for bone tissue engineering [8].

In the present study we describe the fabrication of commercially available PLA-based scaffolds by 3D printing and then in vitro testing in three groups - scaffolds pretreated with complete culture medium, bovine fetal serum and human blood. The quality of prepared scaffolds was controlled by metrotomography to determine the porosity of scaffolds prior seeding cells. The next goal of our study was analysis of cytotoxicity and biocompatibility by using periosteum-derived cells.

\section{Materials and methods}

\subsection{Fabrication of polylactid acid scaffolds}

PLA - Polylactid acid (Plasty Mladeč, Czechia) was used for the preparation of scaffold. PLA is ali- phatic polyester, its values (physicochemical properties, mechanical properties and properties of printing process) are presented in Table 1. Data were obtained from Data sheet and Manufacturer, properties of printing process were set based on own experiment.

Scaffolds for experiment were fabricated by technology FFF, which is one of additive manufacturing technologies. Model of scaffold with dimensions $10 \times 10$ $\times 4 \mathrm{~mm}$ and porosity of $61 \%$ was created in CAD program - Autodesk Inventor Professional (Autodesk, USA). Subsequently, the model of scaffold in *.stl format was transferred to commercially available 3D printer - bq Witbox (Mundo Reader, Spain), followed by printing porous scaffold.

Table 1. Properties of used material and properties of printing process

\begin{tabular}{|l|l|c|}
\hline \multicolumn{3}{|c|}{ Properties of Polylactic Acid } \\
\hline \multirow{3}{*}{$\begin{array}{l}\text { Physicochemical } \\
\text { properties }\end{array}$} & Specific gravity & 1.24 \\
\cline { 2 - 3 } & Glass transition temperature & $60^{\circ} \mathrm{C}$ \\
\cline { 2 - 3 } & Temperature print & $195-225^{\circ} \mathrm{C}$ \\
\hline \multirow{4}{*}{$\begin{array}{l}\text { Mechanical } \\
\text { properties }\end{array}$} & Tensile strength break & $7.7 \mathrm{MPa}$ \\
\cline { 2 - 3 } & Tensile yield strength & $8.7 \mathrm{MPa}$ \\
\cline { 2 - 3 } & Tensile modulus & $500 \mathrm{GPa}$ \\
\cline { 2 - 3 } Properties & Tensile elongation & $6 \%$ \\
\hline \multirow{2}{*}{\begin{tabular}{l} 
of printing process \\
\cline { 2 - 3 }
\end{tabular}} & Temperature of printing & $210^{\circ} \mathrm{C}$ \\
\cline { 2 - 3 } & Print speed of shell & $40 \mathrm{~mm} / \mathrm{min}$ \\
\cline { 2 - 3 } & Print speed of sparse & $90 \mathrm{~mm} / \mathrm{min}$ \\
\hline
\end{tabular}

\subsection{Quality control of scaffolds by metrotomography}

3D printed scaffolds were subjected to metrotomography (CARL ZEISS, Germany) after production to check the internal structure and use this information to determine the porosity of scaffolds. The scaffold was fixed through polystyrene to rotation table that enabled us to isolate measured scaffold and then scaffold was scanned (conditions of metrotomography voltage: $120 \mathrm{kV}$, electric current: $120 \mu \mathrm{A}$, voxel: 16.42 $\mu \mathrm{m}$ and 1000 positions per rotation). The work with measurement data was conducted in software VGStudio MAX (Volume Graphics, Germany).

Calculation of percentage porosity was conducted based on measurements done using metrotomography. Percentage of porosity is a ratio of volume of solid phase and total volume of scaffold, according to the formula [13]:

$$
\text { Porosity of scaffold }=\left(1-\frac{V_{f}}{V_{c}}\right) \times 100 \%,
$$


where: $V_{f}$ - the total volume of the solid phase of scaffold, $V_{c}$ - the total volume of scaffold.

\subsection{Isolation and cultivation of periosteum-derived osteoprogenitor cells}

Periosteum $\left(2 \mathrm{~cm}^{2}\right)$ was harvested from the medial side of the proximal tibia of female patient (55 years) during total knee replacement surgery. The Ethical committee of The University Hospital of Louis Pasteur in Košice approved all procedures, and the patient's informed consent was obtained. The periosteum specimen was transported in medium consisting of highglucose Dulbecco's modified Eagle medium (DMEM; Invitrogen, GIBCO, USA), supplemented with $1 \%$ antibiotic/antimycotic solution (ATB; 10000 units $/ \mathrm{mL}$ penicillin, $10,000 \mu \mathrm{g} / \mathrm{mL}$ streptomycin, and $25 \mu \mathrm{g} / \mathrm{mL}$ amphotericin B; Invitrogen, GIBCO, USA). Periosteum specimen was minced and digested overnight with $0.1 \%$ bacterial collagenase type I (Invitrogen, GIBCO, USA) in DMEM at $37{ }^{\circ} \mathrm{C}$. Subsequently, cells were collected by centrifugation at $150 \times \mathrm{g}$ for $7 \mathrm{~min}$ and seeded 25,000 cells $/ \mathrm{cm}^{2}$ in a $25 \mathrm{~cm}^{2}$ culture flask (T25) containing Alpha-modified Minimal Essential Medium (Invitrogen, GIBCO ${ }^{\circledR}$, USA) supplemented with $10 \%$ foetal bovine serum (FBS, Invitrogen, GIBCO $^{\circledR}$, USA) and 1\% ATB. Non-adherent cells were removed after 5 days by changing the medium. Adherent cells were cultured under standard culture conditions at $37{ }^{\circ} \mathrm{C}$ in $5 \% \mathrm{CO}_{2}$ humidified atmosphere and the medium was replaced every $2-3$ days. Confluent cell layers were dissociated with $0.05 \%$ Trypsin-EDTA solution (Invitrogen, GIBCO ${ }^{\circledR}$, USA) and the number and viability of cells was assessed by TC10 ${ }^{\mathrm{TM}}$ Automated Cell Counter (Bio-Rad Laboratories). Periosteum - derived osteoprogenitor cells (PDO) from the third passage (P3) - were used for the flow cytometry analysis and co-cultivation with scaffold.

\subsection{Flow cytometry analysis}

Immunophenotype characterization of PDO was performed by flow cytometry. After dissociation with Trypsin - EDTA (GIBCO BRL, Life Technologies, Carlsbad, CA), the cells were washed twice with PBS buffer (GIBCO BRL, Life Technologies, Carlsbad, CA) supplemented with $2 \%(\mathrm{v} / \mathrm{v}) \mathrm{FBS}$. Aliquots of $2.0 \times 10^{5}$ cells were incubated with mouse anti-human CD90/FITC,
CD105/PE，CD73/APC， CD26/PE，CD44/FITC, CD45/FITC, CD29/PE, CD11b/FITC and HLA DR/FITC (Miltenyi Biotec GmbH, Bergisch Gladbach, Germany) for $10 \mathrm{~min}$, washed with $1-2 \mathrm{~mL}$ of PBS buffer and centrifuged at $300 \mathrm{~g}$ for $10 \mathrm{~min}$. Resuspended cell pellet was analyzed in a Becton Dickinson FACSCalibur using CellQuest software (Becton Dickinson, California, USA).

\subsection{Cultivation of periosteum derived osteoprogenitors on PLA scaffold}

The first step in the co-culture of cells and scaffolds was their sterilization. The scaffolds were sterilized by cold plasma application (plasma was formed from a mixture of oxygen $3 \%$ and helium $97 \%$, at a voltage of $13 \mathrm{kV}$ and a frequency of $50 \mathrm{~Hz}$ ).

The PLA scaffolds divided in to three groups were transferred into a 24-well culture plates for subsequent incubation with different media in duration of 48 hours at $37{ }^{\circ} \mathrm{C}$ in $5 \% \mathrm{CO}_{2}$ humidified atmosphere. First group was incubated within human serum, second in complete medium containing Alpha-modified minimal essential medium supplemented with $10 \%$ FBS and $1 \%$ ATB, and third in $10 \%$ FBS. After incubation PLA scaffolds were removed from plates, placed on sterile gauze and dried. After drying scaffolds were transferred into a 24 -well culture plates. PDO at density of $3 \times 10^{4}$ cells suspended in $100 \mu \mathrm{l}$ of culture medium were seeded on PLA scaffolds and left to attach for $30 \mathrm{~min}$ at $37{ }^{\circ} \mathrm{C}$ in $95 \%$ air and $5 \% \mathrm{CO}_{2}$ humidified atmosphere. Subsequently, $450 \mu \mathrm{l}$ of cell culture medium was added into each well covering the entire height of scaffold. The PDO were cultivated with PLA scaffold and maintained in static culture for 14 days. The cell culture medium was changed every third day of co-cultivation for proliferation assay and for scanning electron microscopy (SEM) analysis.

\subsection{Control acid-base balance}

The purpose of determining the acid-base balance was to clarify whether degradation of the polymeric matrix had an effect on cell culture growth. In this experiment, the $\mathrm{pH}$ was determined using potentiometric glass electrode measurement. The determination of the acid-base balance took place at 1, 6, 11 and 14 day of co-cultivation of PDO cells and PLA matrix. 


\subsection{Proliferation assay}

The CellTiter 96 AQueous One Solution cell proliferation assay (MTS, Promega Corporation, Madison, WI, USA) was used to measure the proliferative activity of the PDO cultivated with PLA scaffold. In this assay, the MTS tetrazolium compound is bioreduced by cells into a colored formazan product that is soluble in tissue culture medium. After co-cultivation PLA and PDO MTS solution is to be pipetted into each well in ratio $5: 1$ and incubated for $4 \mathrm{~h}$ at $37^{\circ} \mathrm{C}$ in a humidified atmosphere with $5 \% \mathrm{CO}_{2}$. Optical density of the coloured supernatant is directly proportional to the number of living cells in culture was measured on microplate reader (Mithras LB 940 Multimode Microplate Reader) at $490 \mathrm{~nm}$. The three groups of experiments were performed in quadruplicate. Each value represents the mean \pm standard deviation (SD)

\subsection{Scanning electron microscopy}

SEM was used to examine adhesion and proliferation of PDO on PLA scaffold. At 14 days of cocultivation, samples were washed with PBS, fixed with $2.5 \%$ glutaraldehyde (Fluka-Biochemika, Steinheim, Switzerland) in $0.1 \mathrm{M}$ sodium cacodylate buffer (pH 7.2) (Merck-Darmstadt, Hohenbrunn, Germany) at $4{ }^{\circ} \mathrm{C}$ for $72 \mathrm{~h}$ period and post fixed with $1 \%$ osmium tetraoxide (W.C Heraeus GMBH, Hanau, Germany) for $3 \mathrm{~h}$ and washed with PBS. Then samples were immersed in isoamylacetate, dehydrated through and ethanol graded series and critical point dried. Samples dried in a carbon dioxide incubator and then were attached to an aluminium stub and sputter coated with gold prior to observation. The surfaces of PLA scaffold with cells were visualized by scanning electron microscope (SEM, Jeol JSM $7000 \mathrm{~F}$, Japan) at acceleration voltage of $20 \mathrm{kV}$.

\subsection{Statistical analysis}

Statistical analysis was performed by statistical software GraphPad Prism (v. 6, GraphPad Software, Inc., La Jolla, CA) and statistical significance of difference between groups - human serum, bovine foetal serum and complete medium was done using one-way analysis of variance. Data obtained in the cell proliferation assay were expressed by mean \pm standard deviation. Quantitative data was reported as mean \pm standard deviation and statistical significance was considered at $p<0.05$.

\section{Results}

\subsection{Characteristics of scaffolds}

The purpose of determining the dimensions of the internal structure was to determine the real dimensions of the PLA made by additive technology. Dimensions, internal structure and porosity were determined by computed tomography (Figs. 1 and 2). Dimensions of the polymer scaffolds were:

- dimension a (width of scaffold) - 10.006 \pm SD mm;

- dimension b (width of scaffold) - 10.662 \pm SD mm;

- dimension c (height of scaffold) $-3.629 \pm \mathrm{SD}$ mm;

- porosity of scaffold $-56.11 \%$.

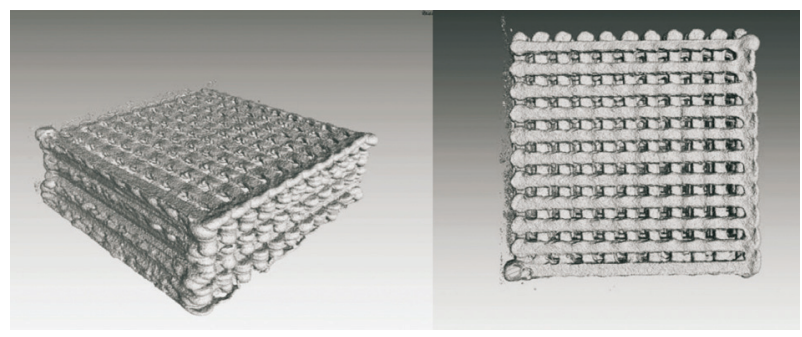

Fig. 1. Printed scaffolds prepared by technology FFF, shown by Computed Industrial Tomography
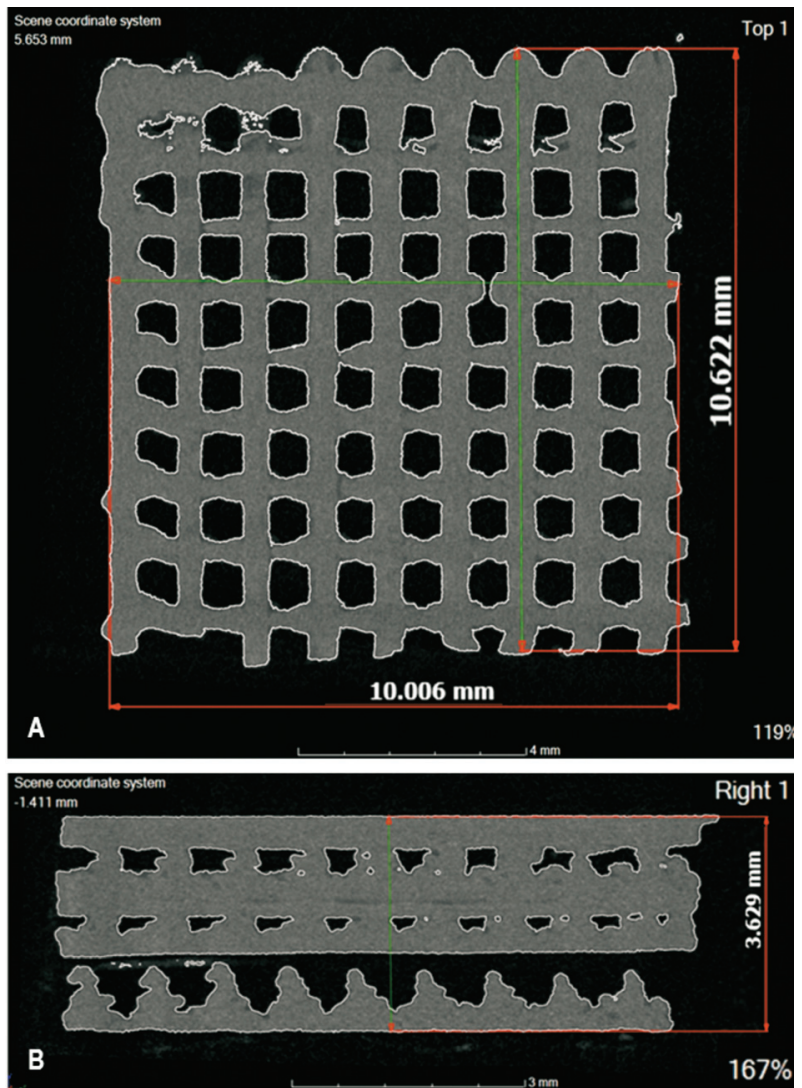

Fig. 2. Grafical outputs of scaffolds-internal structure of scaffold: A) Top View (119\%), B) Right view (167\%) 
The difference between the porosity of the model and the porosity of the real specimen may be due to the material used and overall printing accuracy. For a FFF desktop printer, the printing accuracy is $\pm 0.5 \%$ (lower limit: $\pm 0.5 \mathrm{~mm}$ ). This data are obtain from Manufacter of 3D Printer.

\subsection{Cell culture and characterization of cells}

Periosteal cell cultures were derived as primary cultures from enzymatically released periosteal cell sus-

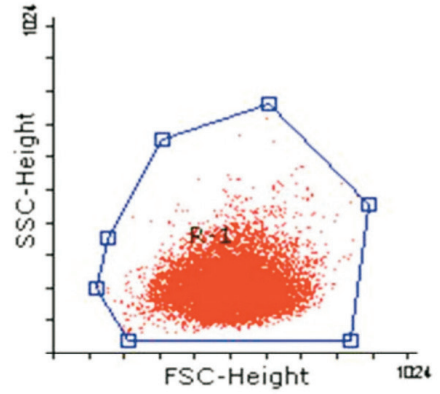

CD 26

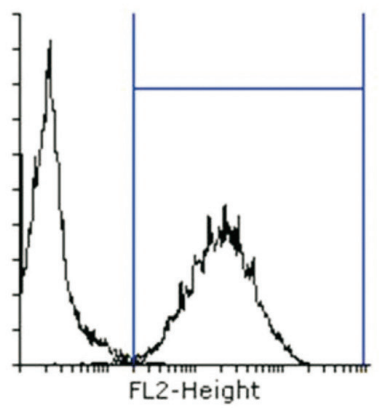

CD 45

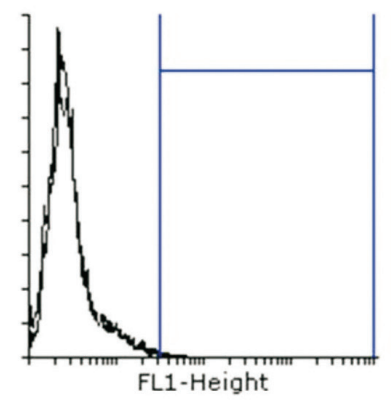

CD 106

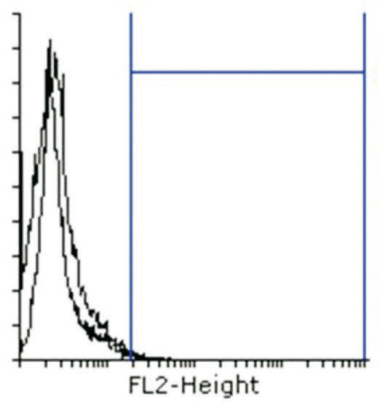

CD 90

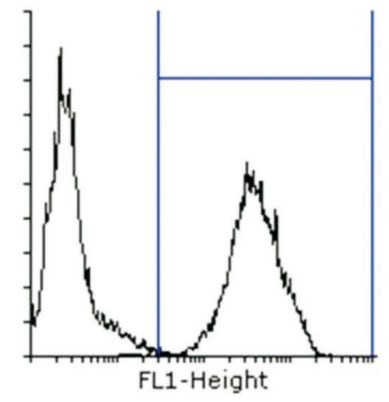

CD 73

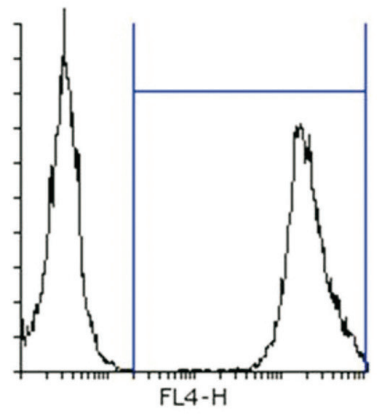

CD 11b

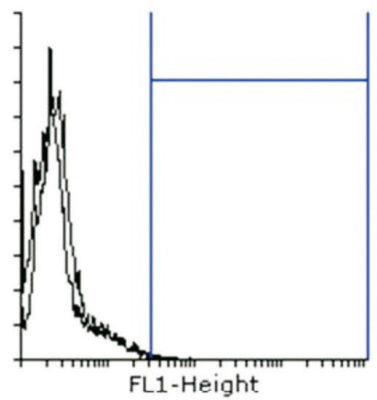

CD 29

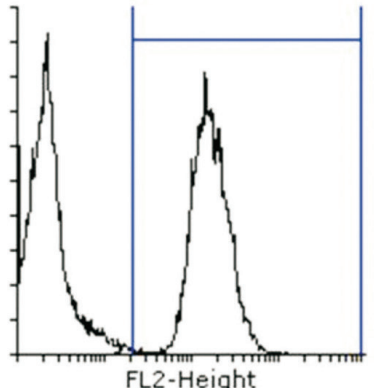

CD 105

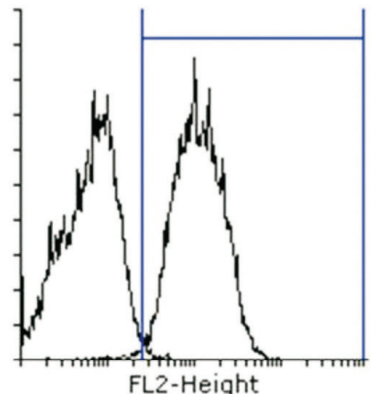

CD 44

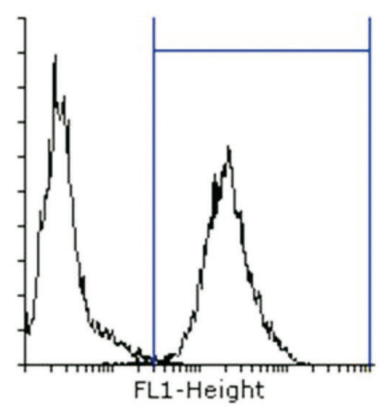

HLA DR

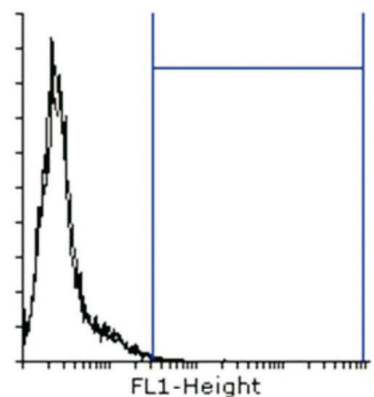

Fig. 3. Flow cytometry characterization of PDOs for CD 90, CD 105, CD 73, CD 44, CD 26, CD 29 and for negative markers CD 45, CD $11 \mathrm{~b}$ and HLA DR 
pensions by selectively attaching to tissue culture plastic. The starting cell concentration of 1000 cells $/ \mathrm{cm}^{2}$ was defined as the optimum concentration for the following monolayer cultivations. After the first passage and throughout in vitro expansion, periosteal cells appeared microscopically to be a relatively homogeneous population of fibroblast-like cells. A sufficient amount of PDO was obtained after third passage for following cultivation with PLA scaffold.

Flow cytometric analysis showed that PDO after third passages were positive for CD90 (99.64\%), CD105 (98.77\%), CD73 (99.52\%), CD26 (98.83\%), CD44 $(99.11 \%), \mathrm{CD} 29(99.9 \%)$ antigens and negative for CD45 (0.38\%), CD11b (0.44\%) and HLA DR (0.47\%) antigens (Fig. 3). These results confirmed that cell isolated from periosteum shared characteristics with mesenchymal stem cells.
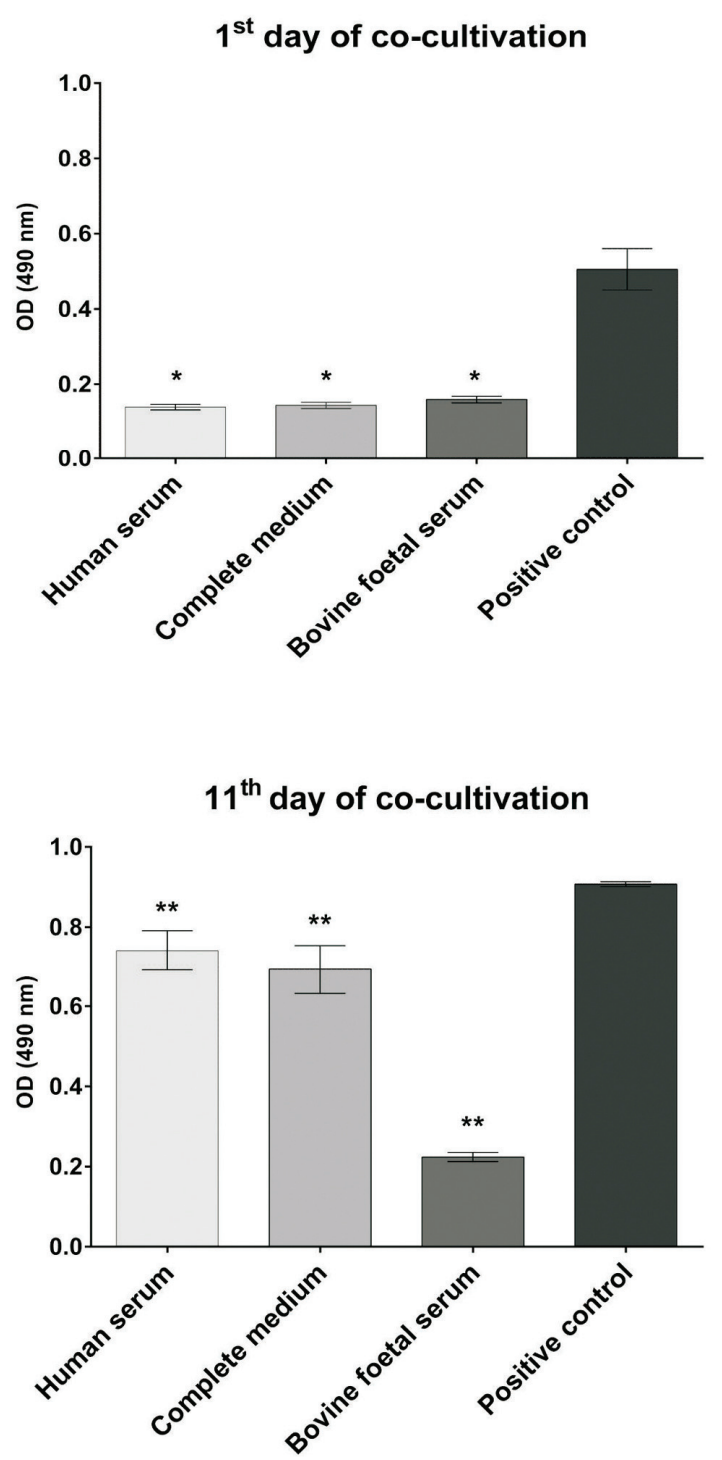

\subsection{Cultivation of periosteum derived osteoprogenitors on PLA scaffolds}

Distribution, adhesion and proliferation of human PDO on the native PLA scaffolds were examined using SEM and MTS after two weeks of co-cultivation. Proliferation and cytotoxicity assay has confirmed that the largest increase of cell number was in group of scaffolds incubated in human serum and co-cultivated in complete cultivation medium with addition of human serum (Fig. 4).

The proliferation of cells was measured throughout co-cultivation for four times and compared to control group of cells. To validate the cell response of PLA scaffolds, the behavior of PDO cultured on the
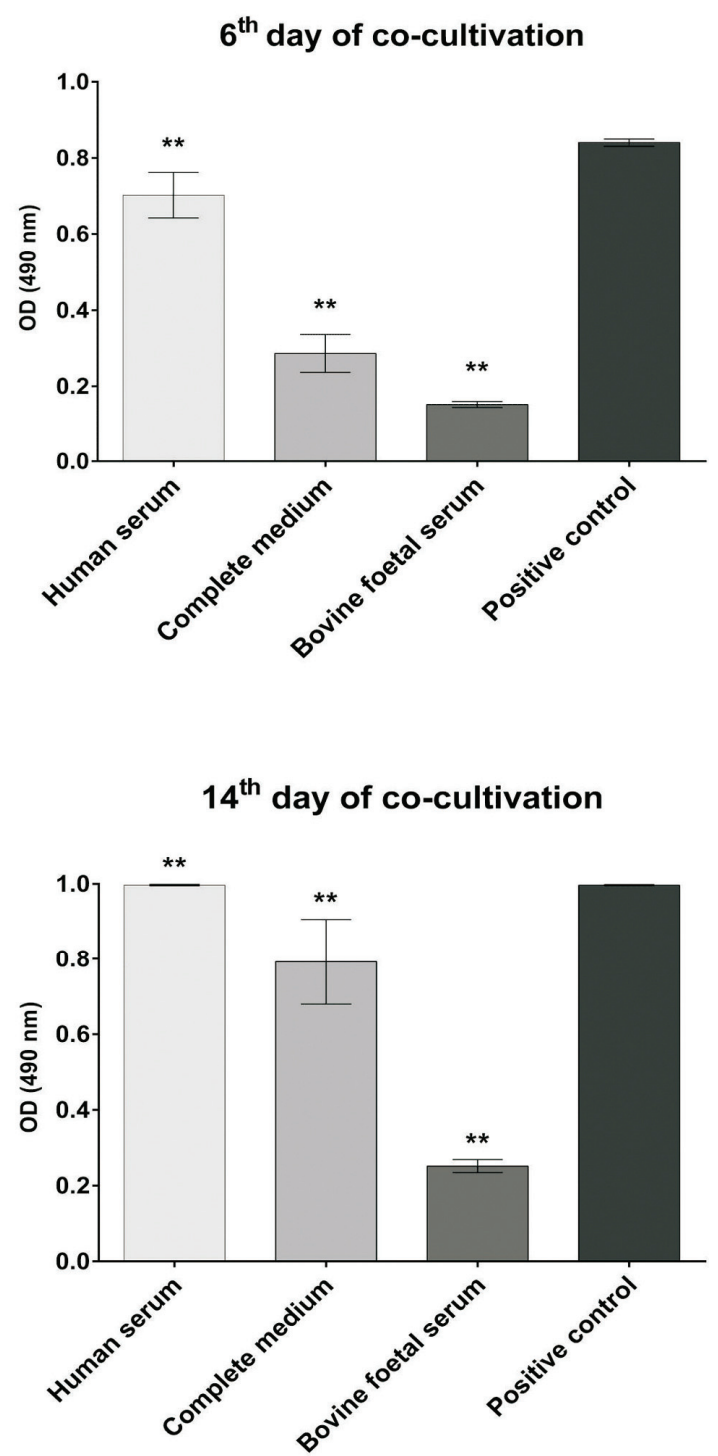

Fig. 4. Proliferation of periosteum derived osteoprogenitors during co-cultivation with PLA scaffolds, measured after 1, 6, 11, and 14 days, respectively by CellTiter $96^{\circledR}$ AQueous One Solution Cell Proliferation Assay. Data represent mean \pm SD value of four independent measures and value of $p$ was $p<0.05$ the first day of co-cultivation $\left(^{*}\right)$ or $p<0.01$ in other days of co-culture $(* *)$ 
scaffolds, including the cell interaction with scaffolds, cell viability, and metabolic activity by MTS assay were evaluated. After $20 \mathrm{~h}$ of the adaptation phase following cell seeding, PDO had already expanded and adhered to the PLA scaffolds, same as in all groups. Subsequently, PDO started to migrate and to proliferate through the pores and integrated well with an inside of matrix on fourth day in the first and second group of sample, in comparison with control group.

\subsection{Control of acid-base balance}

All three control groups had a slightly alkaline $\mathrm{pH}$ at the start of the experiment (after the first day of culture of the cell culture). During the experiment, the $\mathrm{pH}$ was changed in group of complete medium and bovine fetal serum groups (after day 1, it fell slightly on day 6 and subsequently burst and dropped slightly at the end of the experiment). The curve in the human serum group was different: in the first days of the experiment, the $\mathrm{pH}$ of the culture was not changed, but decreased for 11 days.

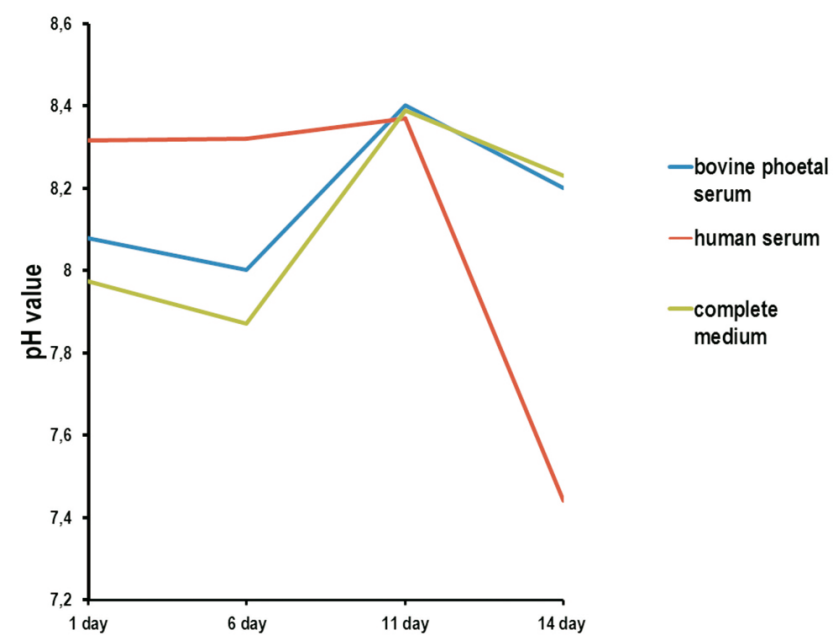

Fig. 5. The measurement of acid-base balance

It was concluded after the experimental application of the most appropriate application of human
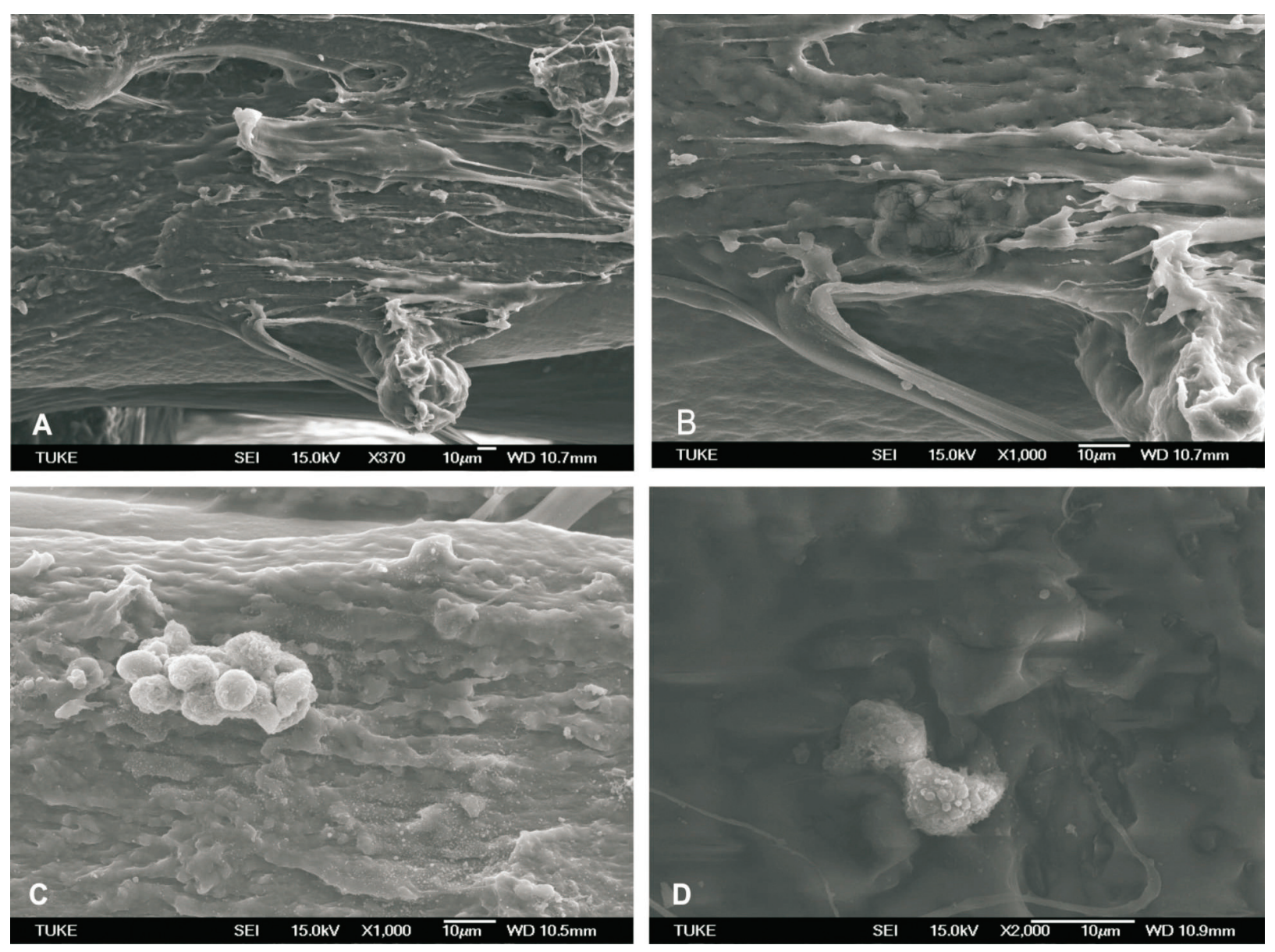

Fig. 6. SEM electronmicrographs of PLA scaffolds with seeded cells demonstrate effective adhesion, spreading and intercellular contact of PDO within the pores PLA scaffold during 14 days cultivation period:

(A) PLA $370 \times,(B, C) 1000 \times$, (D) $2000 \times$ 
serum with human PDO on PLA scaffold that the $\mathrm{pH}$ at the end of the experiment had a value of 7.44 (Fig. 5).

\subsection{Control of adherent cells on the PLA scaffold by SEM}

Cell morphology, spreading and cell-scaffold interaction were studied by SEM. It became relatively difficult to determine the exact boundary of a single cell since the cells grew massively and formed a continuous layer. PDO on the PLA scaffolds expanded even more and almost reached confluence after 14 days in culture (Fig. 6).

\section{Discussion}

Three-dimensional printing is an additive manufacturing that can create complex 3D structures by inject printing of a liquid binder onto powder biomaterials for tissue engineering scaffolds. Direct fabrication of scaffolds from 3DP, however, imposes a limitation on material choices by manufacturing processes. Novel additive manufacturing processes are increasingly recognized as ideal techniques to produce $3 \mathrm{D}$ biodegradable structures with optimal pore size and spatial distribution, providing adequate mechanical support for tissue regeneration while shaping in growing tissues [16]. In this study we printed scaffolds from PLA with defined geometry and porosity. They were tested for cytotoxicity and biocompatibility with periosteum-derived osteoprogenitor cells in order to provide evidence on suitability of PLA scaffolds for bone regeneration.

PLA belong to the most promising biodegradable scaffolding materials owing to its mechanical property profile, thermoplastic processability and biological properties (e.g., biocompatibility and biodegradability) [18]. Other great characteristic of PLA is fact that it can be fabricated from renewable sources [6]. When used as bone tissue engineering scaffolds, PLA scaffold offer a range of attractive features such as large surface area-to-volume ratios, interconnected porous structures, ease of construction into different shapes, and similar structures to natural ECM [15].

Haimi et al. [10] claimed that the PLA is material suitable for applications in tissue engineering, because it has appropriate mechanical properties and also has a suitable degradation profile. Preparations of PLA scaffolds by various techniques were studied by different research teams. For instance, Ni et al. [15] prepared the hybrid PEG/PLA scaffold with fibrous structure by electrospinning. La Carrubba et al. [13] made scaffold of PLA/PEG via thermally induced phase separation. For the purposes of this research PLA scaffolds were produced by technology of additive manufacturing - fused filament fabrication. Subsequently, a percentage porosity of scaffold on $56.11 \%$ as a result of metrotomography was determined. The utilization of $3 \mathrm{D}$ printing technology affected not only porosity of scaffolds but also well-defined internal geometry - distribution and distance between single fibers. Both structural characteristics play crucial role in the biological performances of 3D scaffolds, for instance they effect adhesion, proliferation and differentiation of cells [5].

In the next step of our study, we evaluated the cytotoxicity and biocompatibility. Many authors have described the test of the biocompatibility of the PLA scaffolds with various additives, such as: $\beta$-tricalcium phosphate and bioactive glass [5], or a combination of polylactic acid and polyglycolic acid (PLA/PGA) [21]. However, we could not found a study testing the biocompatibility of the PLA scaffolds in the native status, periosteum derived progenitor cells as in this research. The results showed good biocompatibility of all pretreated scaffolds; however, the best results were obtained in the case of scaffolds pretreated by normal human serum. This finding is very important, mainly from the point of view of potential translation into the human medicine due to elimination of xenogenic and various synthetic factors. Moreover, it was also shown that human serum promotes and supports the proliferation of mesenchymal stem (stromal) cells from different tissue sources [1].

The distribution, adhesion and proliferation of human PDO on the native PLA scaffolds were also examined using SEM observation during two weeks of cultivation. The human PDOs showed good viability in the scaffolds, which were incubated for 48 hours in human serum, which was expressed by enhanced cellular spreading and proliferation and the $\mathrm{pH}$ of media, in which scaffolds and cells were co-cultivated, was 7.4 after 14 days. The $\mathrm{pH}$ reached the value of the one in human blood. Several studies indicate that changes of $\mathrm{pH}$ play crucial roles in proliferation, differentiation and migration of different types of stem cells [14]. It was also shown that $\mathrm{pH}$ microenvironment of stem cells belongs to critical factor of osteogenesis in tissue-engineered constructs [12]. 


\section{Conclusions}

This work was undertaken as a basic in vitro study investigating cultivation periosteum derived osteoprogenitors with porous PLA scaffolds prepared for experiment using FFF technology of additive manufacturing. The obtained PLA porous scaffolds favored attachment periosteum derived progenitors and proliferation, furthermore, cells penetrated into the scaffold through the interstitial pores, which was meaningful for cytocompatibility evaluation. New strategies, such as poly-therapy by using scaffolds, healing promotion factors and stem cells, and finally three-dimensional printings, are in their preliminary stages, but may offer new exciting alternatives in the near future.

\section{Acknowledgements}

This work was supported by Ministry of Education, Science, Research and Sport of the Slovak Republic (VEGA grant No. 1/0179/19), Slovak Research and Development Agency under contracts Nos. APVV 0684-12, APVV-14-0294, APVV-15-0356, and APVV-17-0278.

\section{References}

[1] Athanasiou K.A., Niederauer G.G., Agrawal C.M., Steri lization, toxicity, biocompatibility and clinical applications of polylactic acid/polyglycolic acid copolymers, Biomaterials, 1996, 17, 2, 93-102.

[2] Bidan C.M., Kommareddy K.P., Rumpler M., Kollmannsberger P., Fratzl P., Dunlop J.W.C., Geometry as a Factor for Tissue Growth: Towards Shape Optimization of Tissue Engineering Scaffolds, Adv. Healthc. Mater, 2012, 2, 186-194.

[3] Billiet T., Vandenhaute M., Schelfhout J., Van Vlierberghe S., Dubruel P., A review of trends and limitations in hydrogel-rapid prototyping for tissue engineering, Biomaterials, 201233 (26), 6020-6041.

[4] Dimitriou R., Jones E., McGonagle D., Giannoudis P.V., Bone regeneration: current concepts and future directions, BMC Medicine, 2011, 9 (1).

[5] Domingos M., Intranuovo F., Russo T., Santis R.D., Gloria A., Ambrosio L., Ciurana J., Bartolo P., The first systematic analysis of $3 D$ rapid prototyped poly( $\varepsilon$-caprolactone) scaffolds manufactured through BioCell printing: the effect of pore size and geometry on compressive mechanical behaviour andin vitro hMSC viability, Biofabrication, 2013, 4, 045004 (13 p.).

[6] Drumright R.E., Gruber P.R., Henton D.E., Polylactic Acid Technology, Adv. Mater, 2000, 23, 1841-1846.

[7] El-Rashidy A.A., Roether J.A., Harhaus L., KNeser U., BoCCACCINI A.R., Regenerating bone with bioactive glass scaffolds: A review of in vivo studies in bone defect models, Acta Biomater., 2017, 62, 1-28.
[8] Gregor A., Filová E., Novák M., Kronek J., Chlup H., BuZGO M., Designing of PLA scaffolds for bone tissue replacement fabricated by ordinary commercial $3 D$ printer, J. Biol. Eng., 2017, 1, 1-21.

[9] HaAparanta A.M., Järvinen E., Cengiz I.F., Ellä V., Kokkonen H.T., Kiviranta I., KellomäKi M., Preparation and characterization of collagen/PLA, chitosan/PLA, and collagen/chitosan/PLA hybrid scaffolds for cartilage tissue engineering, J. Mater. Sci., Mater. Med., 2014, 4, 1129-1136.

[10] Haimi S., SuUriniemi N., HaAparanta A.M., Ellä V., Lindroos B., Huhtala H., SuUronen R., Growth and Osteogenic Differentiation of Adipose Stem Cells on PLA/Bioactive Glass and PLA/ $\beta$-TCP Scaffolds, Tissue Eng. Part C, 2009, 7, 1473-1480.

[11] Henkel J., Woodruff M.A., Epari D.R., Steck R., Glatt V., Dickinson I.C., HutMaCheR D.W., Bone Regeneration Based on Tissue Engineering Conceptions - A 21st Century Perspective, Bone Res., 2013, 3, 216-248.

[12] JagielsKa A., Wilhite K.D., VAN Vliet K.J., Extracellular Acidic pH Inhibits Oligodendrocyte Precursor Viability, Migration, and Differentiation, PLoS ONE, 2013, 9, e76048.

[13] La Carrubba V., Pavia F.C., Brucato V., Piccarolo S., PLLA/PLA scaffolds prepared via Thermally Induced Phase Separation (TIPS): tuning of properties and biodegradability, Int. J. Mater. Form, 2008, S1, 619-622.

[14] Monfoulet L.E., Becquart P., Marchat D., VanDamme K., Bourguignon M., Pacard E., Logeart-Avramoglou D., The $\mathrm{pH}$ in the Microenvironment of Human Mesenchymal Stem Cells Is a Critical Factor for Optimal Osteogenesis in Tissue-Engineered Constructs, Tissue Eng. Part A, (13-14), $1827-1840$.

[15] Ni P., Fu S., Fan M., Guo G., Shi S., Peng J., Qian Z., Preparation of poly(ethylene glycol)/polylactide hybrid fibrous scaffolds for bone tissue engineering, Int. J. Nanomed., 2011, 6, 3065-3075.

[16] Oryan A., Alidadi S., Moshiri A., Maffulli N., Bone regenerative medicine: classic options, novel strategies, and future directions, J. Orthop. Surg. Res., 2014, 1, 9-18.

[17] Pilarek M., Grabowska I., Senderek I., Wojasiński M., JANICKA J., JANCZYK-ILACH K., CIACH T., Liquid perfluorochemical-supported hybrid cell culture system for proliferation of chondrocytes on fibrous polylactide scaffolds, Bioprocess Biosyst. Eng., 2014, 9, 1707-1715.

[18] Rodrigues N., Benning M., Ferreira A.M., DiXon L., DAlgarno K., Manufacture and Characterisation of Porous PLA Scaffolds, Procedia CIRP, 2016, 49, 33-38.

[19] Rosenzweig D., Carelli E., Steffen T., Jarzem P., Haglund L., 3D-Printed ABS and PLA Scaffolds for Cartilage and Nucleus Pulposus Tissue Regeneration, Int. J. Mol. Sci., 2015, 12, 15118-15135.

[20] Woodfield T.B.F., Malda J., De Wijn J., Péters F., Riesle J., VAN BLITTERSWIJK C.A., Design of porous scaffolds for cartilage tissue engineering using a three-dimensional fiber-deposition technique, Biomaterials, 2004, 25 (18), 4149-4161.

[21] Zhang Z., CUI H., Biodegradability and Biocompatibility Study of Poly(Chitosan-g-lactic Acid) Scaffolds, Molecules, 2012, 3, 3243-3258.

[22] Kotlarz M., Jordan R., Wegener E., Dobrzyński P., NeunZehn J., Lederer A., Wolf-Brandstetter C., PamuŁa E., Scharnweber D., One step $3 D$ printing of surface functionalized composite scaffolds for tissue engineering applications, Acta Bioeng. Biomech., 2018, 2, 35-45. 
[23] Woźna A.E., Junka A.F., SZyMczyk P.E., The influence of different composite mixtures (PLA/HA) manufactured with additive laser technology on the ability of $S$. aureus and P. aeruginosa to form biofilms, Acta Bioeng. Biomech., 2018, 4, 101-106.

[24] SZAJEK K., WiERSZYCKi M., Numerical verification of two-component dental implant in the context of fatigue life for various load cases, Acta Bioeng. Biomech., 2016, 1, 103-113.

[25] Kasperski J., Rosak P., Rój R., Czelakowska A., Sieroń-StoŁtny K., PaseK J., Sieroń A., The influence of low-frequency variable magnetic fields in reducing pain experience after dental implant treatment, Acta Bioeng. Biomech., 2015, 4, 97-105. 